\title{
Urban-rural differences in questionnaire-derived markers of asthma in Kenyan school children
}

\author{
J.A. Odhiambo*, L.W. Ng'ang'a*, M.W. Mungai*, C.M. Gicheha*, J.K. Nyamwaya*, \\ F. Karimi*, P.T. Macklem+, M.R. Becklake ${ }^{+}$
}

Urban-rural differences in questionnaire-derived markers of asthma in Kenyan school children. J.A. Odhiambo, L.W. Ng'ang'a, M.W. Mungai, C.M. Gicheha, J.K. Nyamwaya, F. Karimi, P.T. Macklem, M.R. Becklake. (OERS Journals Ltd 1998.

ABSTRACT: Grade 4 Kenyan children attending 10 randomly selected public primary schools in Nairobi (urban) and the Muranga District (rural) were surveyed to establish the prevalence of symptom markers of asthma and to assess the impact of urbanization.

A respiratory health and home environment questionnaire was administered at school to parents or guardians. The questionnaire response rates were $94.2 \%(568$ / $603)$ for Nairobi and $89.6 \%(604 / 674)$ for Muranga.

The prevalence rates for asthma, defined as "attacks of shortness of breath with wheeze", were $9.5 \%$ for urban and $3.0 \%$ for rural children (odds ratio (OR) urban versus rural: 3.42; 95\% confidence interval (CI): -1.96-5.91). This urban-rural gradient persisted after adjusting for urban-rural differences in host factors (including duration of breastfeeding and family history of asthma and/or allergy), but was largely explained by urban-rural differences in environmental factors, including indoor animals, sharing a bedroom with a smoker, parental education, house ventilation and exposure to motor vehicle fumes en route to school (adjusted OR: 1.59; 95\% CI: 0.70-3.55). Similar results were obtained for all other symptoms.

These findings confirm the clinical impression that asthma is an important illness in Kenya and underline the need for the further study of environmental factors amenable to intervention, particularly in urban areas.

Eur Respir J 1998; 12: 1105-1112.
*Respiratory Disease Research Unit, Kenya Medical Research Institute, Nairobi, Kenya. 'Respiratory Epidemiology Unit, Dept of Epidemiology and Biostatistics, McGill University, and International Respiratory Disease Research Unit, International Union Against Tuberculosis and Lung Disease (IUATLD), Montreal, Quebec, Canada.

Correspondence: J.A. Odhiambo, Respiratory Disease Research Unit, Kenya Medical Research Institute, P.O. Box 47855 , Nairobi, Kenya, Fax: 2542729308.

Keywords: Asthma, prevalence, schoolchildren, symptom markers, urban versus rural Kenya

Received: June 191997

Accepted after revision June 201998

Funded by the International Development Research Centre (IDRC), Canada. Support for data analysis and report preparation was received from IUATLD. Additional support was received from the Kenya Medical Research Institute (KEMRI).
Although asthma occurs in Africa, prevalence rates and disease determinants across the continent remain largely unknown. From reports published up to 1989 , it was estimated that $2-10 \%$ of children, adolescents and young adults in Africa present each year with one or more episodes of asthma [1]. While the majority of the population on the continent is still rural, most countries are experiencing rapid urbanization with increasingly Westernized lifestyles, which may have a significant impact on the distribution and determinants of childhood asthma. There is also some evidence that the prevalence is increasing in Africa, as has been shown for countries in Europe, North America and Australasia [2-5]. In Kenya, as early as the 1960s, asthma was reported to be the leading cause of emergency visits to the casualty department of the National Hospital in Nairobi [6] and current clinical experience suggests that the disease rates, as well as the number of patients seeking treatment, have since increased [7].

Risk factors are likely to be different in the industrializing countries of Africa compared with the industrialized countries of Europe and North America, where a family history of asthma has been reported to be one of the strongest predictors for asthma in children [8]. In contrast, in a study of 93 asthmatic children conducted in the northern Nigerian city of Zaria, a family history of asthma was reported for only $16 \%$ of the children [9]. This raises two possibilities in which either there are differences in the disease aetiology between industrializing and industrialized countries, or there is an under-reporting of family history of asthma in industrializing countries for social reasons [9]. Likewise, the environmental factors implicated in asthma are also likely to be different. In most of rural Africa, firewood is commonly used for domestic cooking. Much of this fuel is burnt under conditions that favour high indoor concentrations of wood smoke [10] and this may have a significant impact on asthma morbidity. While cigarette smoking is currently declining in industrialized countries, it is increasing rapidly in Africa as the tobacco companies shift their business interests to this market [11]. In view of the association between smoking in the household and continuing asthmatic symptoms in young children, this subject also needs urgent attention in Africa. Another change in lifestyle that may have led to an introduction of house dust mites into sleeping quarters is the replacement of the traditional floor mats by blankets and mattresses. This has been offered as an explanation for the relatively sudden increase in asthma in all ages in Papua New Guinea from $0.9 \%$ in 1972 [12] to $7.3 \%$ in 1984 [13]. Urban studies in Kenyan adults [14] and Tanzanian children [15] show that asthma patients exhibit a high 
prevalence of allergy to house dust mites. By contrast, community-based surveys of exercise-induced bronchospasm in children in Ghana [16] and asthma in the general population in Ethiopia [17] report low rates of sensitization to house dust mites. These differences may be a reflection of lifestyle, i.e. traditional versus Western.

Prior to a pilot study conducted to develop methodology for the present study [18], no study at the community level had been carried out in Kenya to examine the occurrence of asthma and the local determinants for this disease, therefore, also remained largely unknown. This report is based on material gathered as part of a research programme, the primary objective of which was to determine the prevalence and determinants, including risk factors, for the occurrence of asthma in Kenyan schoolchildren and to examine the impact of urbanization. The programme was designed to investigate whether the prevalence of asthma in Kenyan schoolchildren is higher in urban than in rural areas, and if so, to what extent these differences can be attributed to the changes in environmental factors that accompany urban living and a Westernized lifestyle. The present report focuses on the prevalence and the determinants of markers of asthma obtained from a questionnaire administered to the parents and guardians of participating children.

\section{Methods}

\section{Study population}

A cross-sectional design was used to target 10-yr-old school children. The study sites were Muranga District (rural) and Nairobi (urban). Muranga District is located about $80 \mathrm{~km}$ to the north of Nairobi. It was chosen because it shares the same altitude and climatic conditions as Nairobi, altitude being an important determinant of spirometric determinants of airflow [19]. Five schools from Muranga District (rural) and five from Nairobi (urban) were selected at random from school lists supplied by the Ministry of Education and Nairobi City Education Office, respectively. Within Muranga District (422 primary schools), 2 subdistricts, Kandara and Makuyu, were chosen for study because they most closely resemble Nairobi in terms of altitude and climate. From Kandara subdistrict (68 schools), three schools were chosen at random from areas of small agricultural holdings worked by peasants and from Makuyu subdistrict (56 schools), two plantation schools were chosen, one located within a pineapple plantation and the other within a coffee plantation. Nairobi is a city of $>2$ million people with a high population growth arising from both migration from rural areas and a high population growth rate. English is the official language, while Swahili is the language of commerce, although several tribal languages are also spoken in the city. Nairobi supports both light and heavy industry, it is a transport hub in the East and Central African region and there is considerable motor vehicle pollution. The 136 public schools in Nairobi were stratified by neighbourhood socioeconomic class (five levels) as judged by the City Education Office and one school was selected at random to represent each stratum. The majority of grade 4 children in Nairobi were aged $10 \mathrm{yrs}$ but the Muranga population included older children. No child in grade 4 was excluded from the study on account of age.

Clearance to undertake the study was given by the scientific steering and the ethical committees of the Kenya Medical Research Institute in Nairobi. Additional clearance to involve the schoolchildren and their parents in the study was obtained from the Director of Education in Kenya. In Muranga District, where many of the parents were illiterate, group consent to participate in the study was granted by the parents verbally following introductory parents/teachers information meetings addressed by the investigators. In Nairobi, consent to participate in the study in four schools was sought through a letter given to the children to take to their parent or guardian, while in one school (located in the slum area), consent was sought in a manner similar to that used for the rural area.

\section{Questionnaire}

Interviewer-administered questionnaires on the child's respiratory health and home environment characteristics were answered by the parents or guardians of participating children at the respective school compounds. Interviews were conducted by three study team members who, between them, spoke English, Swahili, Kikuyu and Luo. The questions, written in English, were freely translated by the interviewers into the language chosen by the parent or guardian, a method found to give reproducible results in other work done in Africa [20]. In Muranga District, the spoken language was almost exclusively Kikuyu, whereas in Nairobi, English and Swahili were used most frequently. The research team actively followed-up those parents who did not attend the school to complete the questionnaire. Most parents approached in their homes willingly completed the questionnaire. Data collection commenced in January 1993 and was completed by August 1993.

\section{Data management and analysis}

All data collected were entered into a computer through a DBASE III Plus program (1994; Borland International, Scotts Valley, CA, USA) during and at the end of the study. Four markers based on responses to questions concerning wheeze, shortness of breath while playing, attacks of shortness of breath with wheeze and cough that interrupts sleep were identified as outcomes for analyses. The explanatory variable of major interest was area of residence (urban versus rural). Other potential explanatory variables identified a priori included personal characteristics (age and sex), host characteristics such as a personal and family history of allergy and early life characteristics such as preterm birth $(<35$ weeks), duration of breastfeeding and birth weight. Home environment characteristics also identified $a$ priori included exposure to environmental tobacco smoke in the home, exposure to animals in the homestead, details of the child's sleeping area, kitchen characteristics and structural features of the home. The last set of explanatory variables included other socioenvironmental factors such as parental level of education, household crowding and exposure to motor vehicle fumes en route to school.

Statistical analysis was performed using the SAS statistical program [21]. Differences in the prevalence rates for 
markers of asthma between rural and urban children were assessed using Chi-squared tests. Urban-rural comparisons of personal characteristics, host and home environment factors were also made to determine which explanatory variables to use in modelling the urban-rural differences. Categorical variables were compared using Chi-squared tests, while t-tests were used to compare mean values for continuous variables. Statistical significance was defined by a p-value ð0.05 using a two-tailed test. Multiple logistic regression models were then constructed for each marker (dependent variable) in order to examine whether or not the urban-rural differences found in the markers of asthma could be explained by urban-rural differences in the risk factors examined. Personal, host and home environment characteristics were serially included in these models in order to determine the extent to which these factors explained the observed urban-rural differences. All analyses were first performed for males and females separately on a priori grounds, given the commonly reported higher rates in males than in females [8]. The decision to retain a variable in the final model was based on substantive knowledge and/or change in the urban-rural coefficient when the variable was added into the model.

\section{Results}

\section{Participation}

A total of 1,277 eligible school children were identified from the class registers of the selected schools. In the five schools selected from Muranga District, 674 children were eligible and the parents of 604 answered the questionnaire (89.6\% response rate). For Nairobi, 603 children were eligible and the parents of 568 responded to the questionnaire (94.2\% response rate).

\section{Characteristics of the study population}

These are shown in table 1 . The urban children were, on average, younger than their rural counterparts: mean 10.2
(SD 0.9) yrs for urban compared with 11.4 (1.5) yrs for rural children. The sex distribution was comparatively equal for both study sites. Although urban children were more likely to be born prematurely ( $<35$ weeks) they had, on average, a higher mean birth weight than rural children. It should be noted, however, that the question on birth weight was answered by only $55 \%$ of rural and $60 \%$ of urban parents. Urban children were also breastfed for shorter periods than their rural counterparts. In addition, the parents of urban children were more likely than their rural counterparts to report a family history of asthma symptoms and allergy. The urban-rural differences in personal and early life characteristics and family history of asthma and allergy were all statistically significant.

\section{Prevalence of symptom markers of asthma}

Table 2 shows the prevalence of respiratory symptoms and allergy by sex and area of residence. There were statistically significant urban-rural differences in virtually all of the symptoms studied, with higher rates consistently reported for urba children. Overall, males tended to report a higher frequency of symptoms than females, although these sex differences were less dramatic in the urban than the rural area.

\section{Home environment characteristics}

The characteristics of the homes of children studied are shown in table 3 . Significantly fewer urban than rural children were exposed to cigarette smoke at home (35.5 versus 55.6\%). Most of this exposure came from smoking by fathers, since both study sites reported negligible smoking rates by mothers. Sharing sleeping quarters with a smoker, a situation most likely to be found in single-room homes, was equally common in the two study areas. Overall, urban children were less frequently exposed to animals in the

Table 1. - Personal characteristics of the children studied

\begin{tabular}{|c|c|c|c|c|c|c|}
\hline & \multicolumn{2}{|c|}{ Male } & \multicolumn{2}{|c|}{ Female } & \multicolumn{2}{|c|}{ All subjects } \\
\hline & Rural & Urban & Rural & Urban & Rural & Urban \\
\hline $\begin{array}{l}\text { Personal characteristics } n \\
\text { Age yrs }\end{array}$ & 295 & 299 & 332 & 289 & 627 & 588 \\
\hline Mean (SD) & $11.7(1.6)$ & $10.2(0.9)$ & $11.2(1.5)$ & $10.1(0.8)$ & $11.4(1.5)$ & $10.2(0.9) *$ \\
\hline Range & $8-17$ & $8-15$ & $8-16$ & $9-13$ & $8-17$ & $8-15$ \\
\hline $\begin{array}{l}\text { Early life characteristics } n \\
\text { Birth weight } \mathbf{k g}^{\dagger}\end{array}$ & 163 & 176 & 185 & 185 & 348 & 361 \\
\hline $\mathrm{Me}$ & $3.29(0.57)$ & $3.46(0.58)$ & $3.08(0.57)$ & $3.38(0.72)$ & $3.18(0.58)$ & $3.42(0.65) *$ \\
\hline Rang & $2.0-5.0$ & $1.6-5.5$ & $1.0-4.8$ & $1.3-6.0$ & $1.0-5.0$ & $1.3-6.0$ \\
\hline Prematurity and breastfeeding $n$ & 289 & 281 & 315 & 283 & 604 & 564 \\
\hline Prematurity n $(\%)$ & $4(1.4)$ & $8(29)$ & $4(1.3)$ & $17(6.0)^{*}$ & $8(1.3)$ & $25(4.4)^{*}$ \\
\hline s) n (\%) & $12(4.7)$ & 44 (18.6) & $28(9.7)$ & 48 (19.4) & $40(7.3)$ & $92(19.1)^{*}$ \\
\hline Family $\mathrm{h}$ & 258 & 247 & 275 & 258 & 533 & 505 \\
\hline Asthma n (\%) & $31(12.0)$ & $68(27.5)$ & $36(13.1)$ & $74(28.7)$ & $67(12.6)$ & $142(28.1)^{\ddagger}$ \\
\hline Allergy n (\%) & $26(10.2)$ & $69(27.9)$ & $28(10.2)$ & $78(30.8)$ & $54(10.2)$ & $147(29.4)$ \\
\hline
\end{tabular}

*: urban children were, on average, younger, but larger in size (height, weight and body mass index) than rural children. $¥$ : the question on birth weight was answered for only 55\% of rural and $60 \%$ of urban children. Urban children had a higher mean birth weight than rural children $(\mathrm{p}=0.001)$; significantly more urban females were born preterm ( $<35$ weeks) than their rural counterparts $(\mathrm{p}=0.002)$; breast-feeding for $<6$ months was more common in the urban than in the rural area $(\mathrm{p}=0.0001)$. a family history of asthma and allergy was seen more frequently for urban children than rural children $(\mathrm{p}=0.0001)$. 
Table 2. - Prevalence of symptom markers of asthma and allergy by sex and area of residence

\begin{tabular}{|c|c|c|c|c|c|c|}
\hline & \multicolumn{2}{|c|}{ Males } & \multicolumn{2}{|c|}{ Females } & \multicolumn{2}{|c|}{ All subjects } \\
\hline & $\begin{array}{c}\text { Rural } \\
(\mathrm{n}=289) \\
\mathrm{n}(\%)\end{array}$ & $\begin{array}{c}\text { Urban } \\
(\mathrm{n}=282) \\
\mathrm{n}(\%)\end{array}$ & $\begin{array}{c}\text { Rural } \\
(\mathrm{n}=315) \\
\mathrm{n}(\%)\end{array}$ & $\begin{array}{c}\text { Urban } \\
(\mathrm{n}=286) \\
\mathrm{n}(\%)\end{array}$ & $\begin{array}{c}\text { Rural } \\
(\mathrm{n}=604) \\
\mathrm{n}(\%)\end{array}$ & $\begin{array}{c}\operatorname{Urban}^{\dagger} \\
(\mathrm{n}=568) \\
\mathrm{n}(\%)\end{array}$ \\
\hline \multicolumn{7}{|l|}{ Cough } \\
\hline Usual & $9(3.1)$ & $21(7.5)$ & $7(2.2)$ & $16(5.6)$ & $16(2.7)$ & $37(6.5)$ \\
\hline On most days and nights & $22(7.6)$ & $50(17.7)$ & $23(7.3)$ & $49(17.1)$ & $45(7.5)$ & $99(17.4)$ \\
\hline Interrupts sleep & $16(5.5)$ & $43(15.3)$ & $16(5.1)$ & $35(12.2)$ & $32(5.3)$ & $78(13.7)$ \\
\hline \multicolumn{7}{|l|}{ Shortness of breath } \\
\hline While playing & $13(4.5)$ & $24(8.5)$ & $12(3.8)$ & $27(9.4)$ & $25(4.1)$ & $51(9.0)$ \\
\hline More than age mates & $13(4.5)$ & $17(6.0)$ & $10(3.2)$ & $23(8.0)$ & $23(3.8)$ & $40(7.0)$ \\
\hline \multicolumn{7}{|l|}{ Wheeze } \\
\hline Ever & $12(4.2)$ & $41(14.5)$ & $7(2.2)$ & $35(12.2)$ & $19(3.2)$ & $76(13.4)$ \\
\hline On most days and nights & $10(3.5)$ & $31(11.0)$ & $5(1.6)$ & $22(7.7)$ & $15(2.5)$ & $53(9.3)$ \\
\hline Last 12 months (current) & $10(3.5)$ & $34(12.1)$ & $5(7.0)$ & $20(7.0)$ & $15(2.5)$ & $54(9.5)$ \\
\hline \multicolumn{7}{|c|}{ Shortness of breath with wheeze } \\
\hline Ever & $11(3.8)$ & $30(10.6)$ & $7(2.2)$ & $24(8.4)$ & $18(3.0)$ & $54(9.5)$ \\
\hline Last 12 months & $10(3.5)$ & $22(7.8)$ & $4(1.3)$ & $16(5.6)$ & $14(2.3)$ & $38(6.7)$ \\
\hline \multicolumn{7}{|c|}{ Number of attacks in last 12 months } \\
\hline 1 & $3(1.0)$ & $6(2.1)$ & $1(0.3)$ & $7(2.5)$ & $4(0.7)$ & $13(2.3)$ \\
\hline $2-5$ & $6(2.1)$ & $11(3.9)$ & $2(0.6)$ & $7(2.5)$ & $8(1.3)$ & $18(3.2)$ \\
\hline Š6 & $1(0.4)$ & $6(2.1)$ & $1(0.3)$ & $2(0.7)$ & $2(0.3)$ & $8(1.4)$ \\
\hline Diagnosed asthma & $1(0.4)$ & $13(4.6)$ & $0(0.0)$ & $11(3.9)$ & $1(0.2)$ & $24(4.2)$ \\
\hline \multicolumn{7}{|l|}{ Asthma medication } \\
\hline Ever & $1(0.3)$ & $7(2.5)$ & $4(1.3)$ & $2(0.7)$ & $3(0.5)$ & $9(1.6)$ \\
\hline Current & $0(0)$ & $4(1.4)$ & $0(0)$ & $1(0.3)$ & $1(0.2)$ & $5(0.9)$ \\
\hline Herbal (ever) & $0(0)$ & $1(0.4)$ & $0(0)$ & $0(0)$ & $0(0)$ & $1(0.2)$ \\
\hline Chest cold & $71(24.7)$ & $107(41.5)$ & $86(27.4)$ & $97(37.5)$ & $157(26.1)$ & $204(39.5)$ \\
\hline Chest problem & $6(2.1)$ & $33(11.7)$ & $7(2.2)$ & $36(12.6)$ & $13(2.2)$ & $69(12.2)$ \\
\hline Reported allergy & $12(4.2)$ & $55(21.6)$ & $12(3.8)$ & $45(17.9)$ & $24(4.0)$ & $100(19.7)$ \\
\hline Allergic rhinitis & $7(2.4)$ & $33(11.7)$ & $3(1.0)$ & $22(7.7)$ & $10(1.7)$ & $55(9.7)$ \\
\hline Eczema & $13(4.5)$ & $19(6.7)$ & $8(2.5)$ & $19(6.6)$ & $21(3.5)$ & $38(6.7)$ \\
\hline Any respiratory symptom & $26(9.0)$ & $61(21.6)$ & $23(7.3)$ & $61(21.3)$ & $49(8.1)$ & $122(21.5)$ \\
\hline
\end{tabular}

: significant urban-rural differences were seen in virtually all symptoms studied. away from school in the last 12 months.

homestead than rural children (34.1 versus $80.1 \%$ ). However, animals that spent most of the time indoors (mostly cats) were significantly more frequently reported in the urban than the rural homes (urban 11.8 versus rural $2.3 \%$ ). This was not unexpected considering that rural homes had more open yard space in which the cat could spend time outdoors. Sharing a bed was reported less frequently for urban than for rural children $(54.2$ versus $81.6 \%, \mathrm{p}=$ 0.001). Sleeping on a mattress made from allergenic material (feathers, grass, sisal or grain husks) was less frequent in the urban than in the rural area.

Rural homes were mostly constructed using mud $(60.8 \%)$, while the majority of urban homes were made of stone. Urban homes tended to have a higher number of windows per room than did rural homes, although the presumption that this necessarily meant better ventilation for urban homes may not be true, owing to differences in the structure of the houses. Carpets in the home were exclusively reported in the urban setting. Detached kitchens were also almost exclusively observed in the rural area, while most urban homes had a kitchen that was within the main house but separated by a wall and door that could be closed. The majority of rural homes used firewood as the major domestic fuel $(93.4 \%)$ and rarely used gas and electricity $(2.8 \%$ and $1.0 \%$, respectively), while most urban homes used gas and electricity as the major domestic fuel (48.2\% and $34.6 \%$, respectively). Use of kerosene and charcoal was also more frequent in urban than in rural homes. Urban parents were, perhaps not unexpectedly, more educated than rural parents. There was more household crowding in the urban than in the rural area. Children from the urban area were also exposed more frequently to motor vehicle fumes on the way to school than were rural children.

\section{Determinants of urban-rural differences in symptom markers of asthma}

Table 4 shows the results of modelling the urban-rural differences. Unadjusted odds ratios for urban versus rural area of residence for the various symptom markers of asthma considered in this study range from 1.91 (95\% confidence interval (CI) 1.13-3.24) for "shortness of breath while playing" to 4.76 (95\% CI 2.84-7.97) for "ever wheeze" and were all statistically significant. Accounting for age and sex resulted in a slight reduction in these urbanrural gradients. A further reduction in the urban-rural differences in symptom markers of asthma was observed after accounting for host characteristics (breast-feeding for $<6$ months and family history of asthma symptoms and/or allergy) in addition to age and sex; however, the odds ratios (ORs) were still statistically significant (table 5). After adjustment for environmental characteristics (smokers in the bedroom, animals in the homestead, ventilation, parental education and exposure to motor vehicle fumes en route to school), addition of age, sex and host characteristics resulted in further attenuation of the urban-rural 
Table 3. - Home environment characteristics

\begin{tabular}{|c|c|c|c|c|c|c|}
\hline & \multicolumn{2}{|c|}{ Males } & \multicolumn{2}{|c|}{ Females } & \multicolumn{2}{|c|}{ All subjects } \\
\hline & $\begin{array}{l}\text { Rural } \\
\mathrm{n}(\%)\end{array}$ & $\begin{array}{l}\text { Urban } \\
\mathrm{n}(\%)\end{array}$ & $\begin{array}{l}\text { Rural } \\
\mathrm{n}(\%)\end{array}$ & $\begin{array}{l}\text { Urban } \\
\mathrm{n}(\%)\end{array}$ & $\begin{array}{l}\text { Rural } \\
\mathrm{n}(\%)\end{array}$ & $\begin{array}{l}\text { Urban } \\
\mathrm{n}(\%)\end{array}$ \\
\hline Smoking $\mathrm{n}$ & 286 & 279 & 312 & 281 & 598 & 560 \\
\hline Mother smokes & $0(0)$ & $3(1.1)$ & $2(0.6)$ & $1(0.4)$ & $2(0.33)$ & $4(0.71)$ \\
\hline Father smokes & $141(51.8)$ & $88(32.4) *$ & $157(54.1)$ & $71(25.8) *$ & $298(53.0)$ & $159(29.0) *$ \\
\hline Any smoker at home & $148(54.2)$ & $96(38.1)^{*}$ & $166(56.9)$ & $83(32.8)^{*}$ & $314(55.6)$ & $179(35.5) *$ \\
\hline Animals in the homestead $n$ & 289 & 281 & 315 & 285 & 604 & 566 \\
\hline Cat & $79(27.3)$ & $53(18.9) *$ & $90(28.7)$ & $75(26.3) *$ & $169(28.0)$ & $128(22.6)^{*}$ \\
\hline Dog & $121(41.9)$ & $43(15.3)^{*}$ & $315(35.6)$ & $37(13.0)^{*}$ & $233(38.6)$ & $80(14.1)^{*}$ \\
\hline Chicken & $192(66.4)$ & $59(21.0) *$ & 213 (67.6) & $67(23.5) *$ & $405(67.1)$ & $126(22.3) *$ \\
\hline Any animal & $145(50.2)$ & $80(28.5)^{*}$ & $148(47.0)$ & $93(32.6)^{*}$ & $484(80.1)$ & $250(34.1) *$ \\
\hline Indoor animal & $5(1.7)$ & $26(9.3) *$ & $9(2.9)$ & $41(14.4)^{*}$ & $14(2.3)$ & $67(11.8) *$ \\
\hline Animal sleep indoors & $36(12.5)$ & $25(8.9)$ & 36 (11.4) & $41(14.4)$ & 72 (11.9) & $66(11.7)$ \\
\hline Sleeping area characteristics & 289 & 281 & 315 & 285 & 604 & 566 \\
\hline Sleeps in bedroom & $240(83.0)$ & $199(70.8)$ & 279 (88.6) & $189(66.3)$ & $519(85.9)$ & $388(68.6)$ \\
\hline Sleeps in living room & $11(3.8)$ & $22(7.8)$ & $15(4.8)$ & $26(9.1)$ & $26(4.3)$ & $48(8.5)$ \\
\hline Sleeps in kitchen/single room & $38(13.2)$ & $60(21.4) *$ & $21(6.7)$ & $70(24.6) *$ & $59(9.8)$ & $130(22.3) *$ \\
\hline Shares bedroom & $266(92.0)$ & $256(91.1)$ & $301(95.6)$ & $269(94.4)$ & $567(93.9)$ & $525(2.8)$ \\
\hline Shares bedroom with smoker & $11(3.8)$ & $12(4.3)$ & $9(2.9)$ & $9(3.2)$ & $20(3.3)$ & $21(3.7)$ \\
\hline Shares bed & $231(79.9)$ & $141(50.2) *$ & $262(83.2)$ & $166(58.3)^{*}$ & $493(81.6)$ & $307(54.2) *$ \\
\hline No mattress & $21(7.3)$ & $3(1.1)^{*}$ & $18(5.7)$ & $2(0.7)^{*}$ & $39(6.5)$ & $5(0.9)^{*}$ \\
\hline Allergenic mattress & $32(11.1)$ & $3(1.1) *$ & $10(3.2)$ & $1(0.4)^{*}$ & $42(7.0)$ & $4(0.7) *$ \\
\hline Child spends most waking time & 289 & 281 & 315 & 285 & 604 & 566 \\
\hline Kitchen & $143(50.4)$ & $66(23.5)^{*}$ & $144(46.0)$ & $73(25.6) *$ & $287(48.1)$ & $139(24.6) *$ \\
\hline Bedroom or living room & $141(49.7)$ & $215(76.5)$ & $169(54.0)$ & $212(74.4)$ & $310(51.9)$ & $427(75.4)$ \\
\hline \multicolumn{7}{|l|}{ Kitchen characteristics } \\
\hline Kitchen location $n$ & 287 & 280 & 314 & 285 & 601 & 565 \\
\hline Different building & $140(48.8)$ & $15(5.4)$ & $171(54.5)$ & $6(2.1)$ & $311(51.8)$ & $21(3.7)$ \\
\hline Separated by door & $72(25.1)$ & $189(67.5)$ & $74(23.6)$ & $195(68.4)$ & $146(24.3)$ & $384(68.0)$ \\
\hline Separated by wall (no door) & $15(25.1)$ & $7(2.5)$ & $21(6.7)$ & $6(2.1)$ & $36(6.0)$ & $13(2.3)$ \\
\hline Single-room house & $60(20.9)$ & $69(24.6)^{*}$ & $48(15.3)$ & $78(27.4)^{*}$ & $108(18.0)$ & $147(26.0)^{*}$ \\
\hline Domestic fuel $\mathrm{n}$ & 289 & 281 & 315 & 285 & 604 & 566 \\
\hline Wood & $273(94.5)$ & $17(6.1) *$ & $291(92.4)$ & $18(6.3)^{*}$ & $564(93.4)$ & $35(6.2)^{*}$ \\
\hline Charcoal & $85(29.4)$ & $232(82.6) *$ & $88(27.9)$ & $214(75.1)^{*}$ & $173(28.6)$ & $446(78.8) *$ \\
\hline Kerosene & $95(32.8)$ & $225(80.1)^{*}$ & $107(34.0)$ & $235(82.5)^{*}$ & $202(33.2)$ & $460(81.3) *$ \\
\hline Gas & $5(1.7)$ & $135(48.0) *$ & $12(3.8)$ & $138(48.4) *$ & $17(2.8)$ & $273(48.2) *$ \\
\hline Electricity & $2(0.7)$ & $101(35.9)^{*}$ & $4(1.3)$ & $95(33.3)^{*}$ & $6(1.0)$ & $196(34.6)^{*}$ \\
\hline \multicolumn{7}{|l|}{ Home structural characteristics } \\
\hline House type $n$ & 288 & 273 & 314 & 275 & 602 & 548 \\
\hline Mud & $171(59.4)$ & $35(12.8)$ & $195(62.1)$ & $35(12.7)$ & $366(60.8)$ & $70(12.8)$ \\
\hline Wood & $13(4.5)$ & $13(4.8)$ & $9(2.9)$ & $13(4.7)$ & $22(3.7)$ & $26(4.7)$ \\
\hline Stone & $95(33.0)$ & $224(82.1)$ & $95(30.3)$ & $224(81.5)$ & $190(31.6)$ & $448(81.8)$ \\
\hline Other & $9(3.1)$ & $1(0.4)^{*}$ & $15(2.6)$ & $3(1.1)^{*}$ & $24(4.0)$ & $4(0.7)^{*}$ \\
\hline Ventilation $\mathrm{n}$ & 289 & 281 & 315 & 285 & 604 & 566 \\
\hline Number of windows mean (SD) & $4.1(2.1)$ & $4.7(2.6) *$ & $4.3(2.2)$ & $4.6(2.6)$ & $4.2(2.1)$ & $4.6(2.6) *$ \\
\hline Windows per room mean ( $\mathrm{SD}$ ) & $1.1(0.4)$ & $1.3(0.5)^{*}$ & $1.1(0.3)$ & $1.3(0.4)^{*}$ & $1.1(0.4)$ & $1.3(0.5)^{*}$ \\
\hline Carpet & $0(0)$ & $64(22.8)$ & $0(0)$ & $61(21.4)$ & $0(0)$ & $125(22.1)$ \\
\hline Socioenvironmental and characteristics $n$ & 283 & 275 & 313 & 270 & 595 & 545 \\
\hline Household crowding mean (SD) & $2.1(1.1)$ & $2.3(1.6)$ & $1.9(1.0)$ & $2.5(1.8)^{*}$ & $2.0(1.1)$ & $2.4(1.7)^{*}$ \\
\hline Education yrs mean (SD)\# & $6.7(3.4)$ & $11.4(3.2 *)$ & $7.3(3.0)$ & $11.1(3.5)^{*}$ & $7.0(3.2)$ & $11.3(3.3) *$ \\
\hline \multicolumn{7}{|l|}{ Outdoor pollution } \\
\hline Exposed to motor vehicle fumes & & & & & & \\
\hline on the way to school $n$ & 288 & 281 & 314 & 285 & 602 & 566 \\
\hline Frequently & $23(8.0)$ & $191(68.0)$ & $22(7.0)$ & $189(66.3)$ & $45(7.5)$ & $380(67.1)$ \\
\hline Sometimes & $138(47.9)$ & $81(28.8)$ & $140(44.6)$ & $81(28.4)$ & $278(46.2)$ & $162(28.6)$ \\
\hline Rarely & $127(44.1)$ & $9(3.2)^{*}$ & $152(48.4)$ & $15(5.3) *$ & $279(46.3)$ & $24(4.2)^{*}$ \\
\hline
\end{tabular}

: animal that spends most of the time indoors. domestic fuel ever used in the household. \#: education of parent/guardian (head of household). *: significant $(\mathrm{p}<0.05)$ urban-rural difference.

gradient and the ORs were no longer significant, but all remained $>1.0$. For instance, for "shortness of breath with wheeze (ever)" the unadjusted OR for urban versus rural was 3.42 (95\% CI 1.96-5.91) and when adjusted for age and sex decreased to 2.80 (1.54-5.07). After adjusting for the host factors mentioned above, the OR decreased to 2.38 (1.22-4.64) and after adjusting for environmental characteristics, it decreased further to $1.59(0.70-3.55)$.

\section{Discussion}

The high participation rates attained in the present study lend confidence to reporting the prevalence of the markers of asthma in what is, to our knowledge, the first community-based asthma survey in Kenya. Sensitivity to the social, cultural and economic circumstances of the participating communities was thought to have contributed to the 
Table 4. - Odds ratios (unadjusted and adjusted) with $95 \%$ confidence interval $(\mathrm{Cl})$ for urban versus rural residence, for various symptom markers of asthma

\begin{tabular}{lcccc}
\hline & \multicolumn{4}{c}{ Odds ratio } \\
\cline { 2 - 5 } & Unadjusted & $\begin{array}{c}\text { Adjusted for age } \\
\text { and sex }\end{array}$ & $\begin{array}{c}\text { Adjusted for age, } \\
\text { sex and host } \\
\text { characteristics }\end{array}$ & $\begin{array}{c}\text { Adjusted for age, } \\
\text { sex, host and } \\
\text { environmental } \\
\text { characteristics } \\
\text { n=920 }\end{array}$ \\
Markers of asthma & $\mathrm{n}=1172$ & $\mathrm{n}=1172$ & $\mathrm{n}=939$ & \\
\hline Wheeze & & & & \\
$\quad$ Ever & $4.76(2.84-7.97)$ & $3.76(2.16-6.56)$ & $2.96(1.59-5.50)$ & $1.87(0.88-3.98)$ \\
$\quad$ Persistent & $4.04(2.25-7.26)$ & $3.24(1.72-6.12)$ & $2.64(1.28-5.42)$ & $1.87(0.77-4.56)$ \\
$\quad$ Current & $4.13(2.30-7.40)$ & $3.33(1.76-6.28)$ & $2.23(1.01-4.53)$ & $1.36(0.58-3.20)$ \\
Shortness of breath while playing & $1.91(1.13-3.24)$ & $1.77(0.99-3.18)$ & $1.61(1.14-3.25)$ & $1.19(0.55-2.59)$ \\
Cough that interrupts sleep & $2.85(1.85-4.37)$ & $2.29(1.43-3.65)$ & $1.93(1.14-3.25)$ & $1.13(0.59-2.16)$ \\
Shortness of breath with wheeze & & & & \\
$\quad$ Ever & $3.42(1.98-5.91)$ & $2.80(1.54-5.07)$ & $2.38(1.22-4.64)$ & $1.59(0.70-3.55)$ \\
$\quad$ Current & $3.02(1.62-5.64)$ & $2.52(1.27-5.00)$ & $2.08(0.97-4.49)$ & $1.17(0.48-2.89)$ \\
Any of above symptom & $3.40(2.34-4.94)$ & $2.52(1.71-3.70)$ & $1.97(1.28-3.05)$ & $1.24(0.71-2.14)$
\end{tabular}

: odds ratios were calculated with rural children as the reference category. $\because$ : host characteristics were breast-feeding for $<6$ months and a family history of asthma symptoms and/or allergy. \#: environmental characteristics were sharing a bedroom with a smoker, presence of animals (mostly cats and dogs) that spend time indoors, ventilation (number of windows per room), parental education (yrs) and exposure to motor vehicle fumes on the way to school.

high participation rates [22]. In addition, clearance to undertake this study by Kenya's Director of Education and other related authorities contributed in no small way to the high participation rates achieved. From this experience, it is clear that the methods of conducting field research established in Western countries may not easily or necessarily be used in Africa.

The present study shows that the prevalence of attacks of shortness of breath with wheeze (a symptom complex which most closely approximates a clinical definition of asthma) was $3.0 \%$ and $9.5 \%$ for rural and urban children, respectively. The stratified sampling method adopted in this study did not overestimate or underestimate the prevalence estimates. For instance, for the urban area, the overall prevalence for "shortness of breath with wheeze" was essentially the same as the prevalence estimate weighted for sample size for each school (each of which represented a socioeconomic stratum). Therefore, there is some confidence that the stratified sampling method did not lead to an overestimation of statistical significance in the analysis.

The prevalence rates observed in the current study are at the upper range of published questionnaire-based estimates for Africa $[1,23]$ and at the lower range of the 10-
$20 \%$ cited for Western countries [24]. Note that these comparisons must be guarded, given that they are based on the use of questionnaires which were not standardized and are known to be both culture and language sensitive. Nevertheless the picture created by previous reports [24, 25 ] that asthma is a rare illness among African children can no longer be sustained. In additional, although the rates among rural children were between one-third and onequarter of those reported for urban children, they still indicate an important symptom burden.

In both males and females, all symptoms associated with asthma were more frequent in urban than in rural children, despite the fact that rural children were more frequently exposed than their urban counterparts to cigarette smoke and to pets in the home, both of which are recognized environmental risk factors for childhood asthma $[26,27]$. Part of the explanation of this paradox may lie in the longer duration of breast-feeding among rural than urban children (only $7.3 \%$ of rural compared with $19.1 \%$ of urban children were breastfed for $<6$ months), given the evidence that the protective effect of breast-feeding against lower respiratory tract infections is strongest in children exposed to environmental tobacco smoke [28]. This is also in keeping with a study in Guinea-Bissau, which

Table 5. - Odds ratios (unadjusted and adjusted) with 95\% confidence intervals (Cl) for various risk factors for symptom markers of asthma

\begin{tabular}{|c|c|c|c|c|}
\hline \multirow[b]{2}{*}{ Characteristics } & \multirow[b]{2}{*}{$\mathrm{n}$} & \multicolumn{3}{|c|}{ Odds ratio $(95 \% \mathrm{CI})$} \\
\hline & & Unadjusted & $\begin{array}{c}\text { Adjusted } \\
n=920\end{array}$ & $\begin{array}{c}\text { Adjusted }^{\#} \\
\mathrm{n}=920\end{array}$ \\
\hline Breast-fed for $<6$ months & 1029 & $1.53(0.80-2.94)$ & $1.02(0.49-2.12)$ & $0.98(0.47-2.05)$ \\
\hline Family history of asthma symptoms and/or allergy & 1050 & $4.85(2.84-8.29)$ & $3.36(1.88-6.01)$ & $3.30(1.84-5.89)$ \\
\hline Shares bedroom with a smoker & 1170 & $5.55(2.60-11.84)$ & $4.06(1.47-11.21)$ & $4.03(1.45-11.20)$ \\
\hline Presence of animals that spend time indoors $\S$ & 1170 & $2.65(1.33-5.26)$ & $1.44(0.62-3.32)$ & $1.34(0.58-3.11)$ \\
\hline House ventilation (windows per room) & 1170 & $1.67(1.01-2.76)$ & $1.14(0.58-2.23)$ & $1.13(0.59-2.20)$ \\
\hline Parental education yrs & 1141 & $1.12(1.05-1.20)$ & $1.04(0.96-1.13)$ & $1.02(0.94-1.12)$ \\
\hline Exposure to motor vehicle fumes on the way to school & 1168 & & & \\
\hline Frequently & & $6.19(2.41-15.88)$ & $3.46(1.25-9.55)$ & $2.66(0.87-8.09)$ \\
\hline Sometimes & & $3.90(1.48-10.24)$ & $1.98(0.71-5.51)$ & $1.75(0.61-5.01)$ \\
\hline Never & & Reference & Reference & Reference \\
\hline
\end{tabular}

$¥$ : shortness of breath with wheeze (ever); : adjusted for all other characteristics in the table; \#: adjusted for area of residence as well as all other characteristics in the table; $\$$ : mostly cats and dogs. 
showed breast-feeding for $>12$ months to be protective against the development of atopy and asthma among young people followed up in their teens. Yet another protective factor (not addressed in the present study) in the rural areas may have been the lower rates of vaccination for measles $(18.6 \%$ in rural versus $43.4 \%$ in urban children) [29]. Another explanation could be the higher susceptibility of urban children, as evidenced by the higher frequency of family history of asthma symptoms and/or allergy. Other possible explanations include the exposure of urban children to higher levels of indoor aeroallergens and irritants resulting from indoor animals, sharing a bedroom with a smoker (in single-roomed houses), the use of domestic fuels such as kerosene and charcoal, as well as carpets (which may harbour house dust mites), all of which were more common in urban than in rural homes. Cultural and lifestyle differences between urban and rural communities, which were not exhaustively studied here, cannot be ruled out. These findings are in keeping with a hypothesis gaining increasing credence that the increases in asthma prevalence and, apparently, in its incidence, are likely to be attributable not only to "a more toxic environment", long regarded as the culprit, but also to "a more susceptible population" [30]. The present findings are also in keeping with the results of a recent community-based study of over 9,000 rural and urban residents of Ethiopia, almost 3,000 of whom were children $<10$ yrs of age [17].

From the results of the step-wise adjustment of the urban-rural gradient in symptom markers of asthma in the present study, the urban-rural differences could largely, although not fully, be explained by urban-rural differences in the distribution of known determinants and risk factors. Both host and environmental factors were implicated, with likely effects on the incidence and prevalence of the symptom markers of asthma, respectively [31]. The two host risk factors identified as contributing to higher rates in urban children were a family history of asthma or allergy in at least one family member (parent or sibling) and a shorter period of breast-feeding. A family history is an important determinant of atopy which, in turn, is an important if not the only established genetically determined risk factor for asthma [32]. The higher frequency of a reported family history in urban than in rural children raises the interesting possibility that urban living, with its attendant changes in lifestyle, diet, homes and public buildings and/or working environments, as well as the effects of industrial activity on the quality of urban air, has increased the susceptibility of the parents to develop atopy and atopic illnesses such as asthma, and that this increased susceptibility was passed on to their children. Furthermore, in the present study, urban-rural differences in the frequency of a family history of atopy accounted for an important proportion of the urban-rural differences in the prevalence of symptom markers of asthma (see table 5).

The environmental factors that probably contributed to the urban-rural gradient included sharing a bedroom with a smoker, the presence of indoor animals and pets, and exposure to motor vehicle fumes on the way to school (table 5). The first two variables re-emphasize the fact that it is not just the presence of the source indoor irritant or allergen that matters; rather, it is the environmental circumstances under which they occur. Thus, the presence of animals and smokers in the home was more common in rural than in urban homes, while indoor animals and shar- ing quarters with a smoker were more common in urban than in rural homes.

The hypothesis that parasitosis can provide immunological protection against asthma has been entertained over several decades in the context of the low rates of childhood asthma previously reported for low-income countries [13]. The fact that rates of parasitization have been shown to be comparable in asthmatic and nonasthmatic subjects has been cited as evidence, not necessarily conclusive, against this hypothesis [33, 34]. Information regarding parasitic infestation of the child and/or siblings, as well as other life events including measles [29] and other vaccinations [35] implicated in the genesis of childhood asthma in recent studies, were not addressed in the present study and should be addressed in future Kenya studies.

This report, thus, shows that childhood asthma is not rare in Kenya. Indeed, the high prevalence rates for its symptom markers confirm the clinical impression of its importance and justify the need for study of risk factors in the urban home environment that are amenable to intervention. The prevalence rate of asthma in the urban area reported here, based on an affirmative response to attacks of shortness of breath with wheeze $(9.5 \%)$, is comparable to the prevalence rate of exercise-induced bronchospasm (EIB) of $10.5 \%$ reported recently for the pilot phase of this study [18].

Hospital-based data for any disease, asthma included, have inherent selection bias and are not representative of the burden of disease in the general population. For instance, in 1983, it was estimated that only $10 \%$ of asthma cases in need of medical care actually visited health facilities in East Africa [36]. Although the pattern of hospital visits was not specifically addressed here, if the $10 \%$ above represents the proverbial tip of the iceberg, the findings of the present study provide a good insight into the magnitude of the asthma burden remaining submerged, as it were, in the Kenyan community. This is an important consideration, especially when addressing the rational evaluation of the social and medical costs of asthma in the African context. In addition, in the present study, only one of the 18 rural children and only 24 of the 54 urban children, for whom attacks of shortness of breath with wheeze was reported, had also been diagnosed by a doctor as having asthma. The overall low prevalence of doctor-diagnosed asthma in both rural and urban school children is surprising and possible explanations include a lack of confidence on the part of Kenya clinicians in diagnosing asthma or, more importantly, a serious gap in the quality of doctor-patient communication as part of judicious asthma management. Yet another possibility in the African context is underreporting on the part of parents or guardians, for social reasons [9].

In this study, an urban-rural gradient for various symptom markers of asthma was documented with rates ranging from 1.5 to 3-times more frequently in urban than in rural children. Additional studies are required to elucidate this, especially the role of air pollution and urban lifestyles. This will provide useful information in developing guidelines for the management of asthma in Kenya and other low-income countries, a subject currently being addressed by the International Union Against Tuberculosis and Lung Disease (IUATLD) [37]. 
Acknowledgements: The authors thank the Ministry of Education (Kenya), Nairobi City Education Office, school teachers, parents and pupils of participating schools for their enthusiasm, cooperation and support, and the Director of KEMRI for permission to publish this work.

\section{References}

1. Chaulet P. Asthma and chronic bronchitis in Africa: evidence from epidemiologic studies. Chest 1989; 96: Suppl., 334S-339S.

2. Peat JK, Woolcock AJ, Leader SR, Blackburn CRB. Asthma and bronchitis in Sydney school children. Am J Epidemiol 1980; 11: 721-727.

3. Hsieh KH, Shan JJ. Prevalence of childhood asthma in Taipei and other Asian Pacific countries. J Asthma 1988; 25: 73-82.

4. Sears MR. The epidemiology of childhood asthma. Lancet 1997; 350: 1015-1020.

5. Pearce N, Weiland S, Keil U, et al. Self reported prevalence of asthma symptoms in children in Australia, England, Germany and New Zealand: an international comparison using the ISAAC protocol. Eur Respir $J$ 1993; 6: 1455-1461.

6. Wasunna AEO. Asthma as seen at the casualty department, Kenyatta National Hospital, Nairobi. E Afr Med J 1968; 45: 701-705.

7. Odhiambo JA, Ng'ang'a LW, Gikonyo BM. Efficacy and safety of inhaled salmeterol (Serevent) as maintenance therapy for asthma in Nairobi. E Afr Med J 1994; 71: 8892.

8. Woolcock AJ. Asthma. In: Murray JA, Nadel J, eds. Textbook of Respiratory Medicine, 2nd Edn. Philadelphia, PA, WB Saunders, 1994; pp. 1288-1330.

9. Abdulrrahman MB, Tagi AM. Childhood bronchial asthma in Northern Nigeria. Clin Allergy 1974; 4: 171-183.

10. Boleij JSM, Brunekreef B. Domestic pollution as a factor causing respiratory health effects. Chest 1989; 96: Suppl., 368S-372S.

11. McKay J. Tobacco: the third world war (Editorial). Tho$\operatorname{rax} 1991$; 46: 153-156.

12. Anderson HR. The epidemiological and allergic features of asthma in New Guinea Highlands. Clin Allergy 1974; 4: 171-183.

13. Turner KJ, Dowse GK, Stewart GA, Alpers MP, Woolcock AJ. Prevalence of asthma in South Fore people of the Okapa District of Papua New Guinea. Features associated with a recent dramatic increase. Int Arch Allergy Appl Immunol 1985; 77: 158-162.

14. Rees PH, Gitoho F, Mitchel HS, Rees CH. Some aspects of the aetiology of asthma in Nairobi with special reference to parasites and house dust mite. E Afr Med J 1974; 51: 729-733.

15. Shao JF, Shayo A. Allergen skin tests to asthmatic children screened at Muhimbili Medical Centre, Dar-esSalaam, Tanzania. E Afr Med J 1985; 62: 387-391.

16. Addo Yobo E, Custovic A, Taggart S, Asafo-Agyei A, Woodcock A. Exercise induced bronchospasm in Ghana: differences in prevalence between urban and rural schoolchildren. Thorax 1997; 52: 161-165.

17. Yemeneberhan H, Bekele Z, Venn Andrea, Levis S, Parry
E, Britton J. Prevalence of wheeze and asthma and relation to atopy in urban and rural Ethiopia. Lancet 1997; 350: 85-90.

18. Ng'ang'a LW, Odhiambo JA, Omwega MJ, et al. Exercise induced bronchospasm: a pilot survey in Nairobi school children. E Afr Med J 1997; 74: 694-698.

19. White NW, Hanley JJ, Lalloo UG, Becklake MR. A review and analysis of variation between spirometric values reported in 29 studies of healthy African adults. Am J Respir Crit Care Med 1994; 150: 348-355.

20. Becklake MR, Freeman S, Goldsmith C, et al. Respiratory questionnaires in occupational studies: their use in multilingual workforces on the Witwatersrand. Int J Epidemiol 1987; 16: 606-611.

21. SAS Statistical Program. Cary, NC, SAS Institute, 1985.

22. Odhiambo J, Ng'ang'a L, Mungai M, et al. Rural and urban respiratory health surveys in Kenya school children: participation rates and prevalence of markers of asthma. Am J Respir Crit Care Med 1994; 149: A385.

23. Becklake MR. International Union Against Tuberculosis and Lung Disease (IUATLD): initiatives in non-tuberculous disease. Tubercle Lung Dis 1995; 76: 493-504.

24. Sears MR. Chapter 2. Epidemiology of asthma. In: O'Byrne PM, ed. Asthma as an Inflammatory Disease. New York, Marcel Dekker, 1990.

25. Mitchell H. Bronchial asthma in Kenya. E Afr Med $J$ 1970; 47: 142-145.

26. Verhoef AP, von Strien R, Brunekreef B, von Winjen JH. Reported frequency of allergen avoidance measures in the homes of children with chronic respiratory symptoms and asthma. Am Rev Respir Dis 1992; 145: A533.

27. McConnochi KM, Roghmann KJ. Breast feeding and maternal smoking as predictors of wheezing in children aged 6-10 years. Paediatr Pulmonol 1986; 2: 260-268.

28. Nafstad P, Jaakkola JJK, Hagen JA, Botten G, Kongerud J. Breastfeeding, maternal smoking and lower respiratory tract infections. Eur Respir J 1996; 9: 2623-2629.

29. Shaheen SO, Abby P, Hall AJ, et al. Measles and atopy in Guinea-Bissau. Lancet 1996; 347: 1792-1796.

30. Seaton A, Godden DJ, Brown K. Increase in asthma: a more toxic environment or a more susceptible population? Thorax 1994; 49: 171-174.

31. Becklake MR, Ernst P. Environmental Factors. Lancet 1997; 350 (Suppl. II): 10-13

32. Burney P. Why study the epidemiology of asthma? Tho$\operatorname{rax} 1988$; 43: 425-428.

33. Cookson JB. Prevalence rates of asthma in developing countries and their comparison with those in Europe and North America. Chest 1987; 91: Suppl., 97S-103S.

34. Carswell F, Merrett J, Merrett TG, Meakins RW, Harland PSEG. IgE, parasites and asthma in Tanzanian children. Clin Allergy 1977; 7: 445-453.

35. Cookson WOCM, Moffatt MF. Asthma: an epidemic in the absence of infection? Science 1997; 275: 41-42.

36. Nordberg EM. True disease pattern in East Africa, Part 2. E Afr Med J 198; 60: 530-535.

37. Ait-Khaled N, Enarson D. Management of asthma in adults. A guide for low income countries. International Union Against Tuberculosis and Lung Disease (IUATLD). Frankfurt am Main, pmi-Verlagsgruppe, 1996. 